\title{
CrystEngComm
}

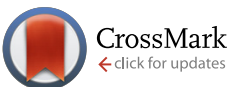

Cite this: CrystEngComm, 2015, 17, 5551

Received 26th March 2015, Accepted 15th June 2015

DOI: $10.1039 / c 5 c e 00598 a$

www.rsc.org/crystengcomm

\section{Fabrication of self-standing films consisting of enamel-like oriented nanorods using artificial peptide}

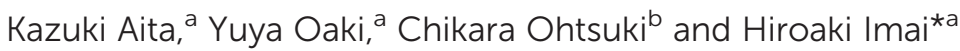

\begin{abstract}
We achieved the fabrication of enamel-like films consisting of c-axis-oriented hydroxyapatite (HA) nanorods by a two-step controlled crystal growth method with the monolayer of a specific artificial peptide binding to the $c$ face of HA. Self-standing films were formed under the monolayer at the air-water interface in an aqueous solution system that was based on a simulated body fluid. The presence of fluoride ions promoted the arrangement of apatite microrods in the $c$ direction through geometric selection. The subsequent growth with aspartic acid produced the enamel-like structure consisting of $c$-axis-oriented nanorods on the basal microrods. Therefore, the controlled crystal growth using the aqueous system including the specific artificial peptide, fluoride ion, and aspartic acid is regarded as a novel fabrication route for wellorganized architectures.
\end{abstract}

\section{Introduction}

Hydroxyapatite $\left(\mathrm{Ca}_{10}\left(\mathrm{PO}_{4}\right)_{6}(\mathrm{OH})_{2}, \mathrm{HA}\right)$ is the main mineral component of the hard tissues of mammals. Slender and long HA nanocrystals are assembled with collagen fibers in their natural structures. The dental enamel surface, the outermost layer of teeth, is covered with well-organized rod-like prisms composed of highly oriented bundles parallel to the $c$ axis of HA crystals. ${ }^{1}$ HA structures having a specific $c$-axis orientation are also observed in various parts of bones. ${ }^{2}$ The proteins produced by ameloblasts in teeth work as a matrix to guide the growth direction of HA. Osteocalcin, i.e., the most abundant non-collagenous protein of the bone's extracellular matrix, has been suggested to regulate the crystal growth of HA via specific adsorption on the $c$ face. Specific macromolecules finely control the nucleation and the crystal growth of HA. Proteins and their related molecules could be utilized as regulators for use in biomaterial engineering.

Several peptides binding to a specific atomic arrangement were used to fabricate nanoscale materials. ${ }^{3}$ Gungormus et al. reported the amino acid sequence of HA-attaching peptides that are identified by using phage display. ${ }^{4}$ An artificial linear peptide (NPPTRQTKPKRVANTN) binding to the $c$ face of HA was obtained using the mRNA display method. ${ }^{5}$ The

\footnotetext{
${ }^{a}$ Department of Applied Chemistry, Faculty of Science and Technology, Keio University, 3-14-1 Hiyoshi, Kohoku-ku, Yokohama 223-8522, Japan. E-mail: hiroaki@applc.keio.ac.jp

${ }^{b}$ Department of Crystalline Materials Science, Graduate School of Engineering, Nagoya University, Furo-cho, Chikusa-ku, Nagoya 464-8603, Japan
}

results of this study suggest that the amino acid sequence including Ala-Asn-Thr (ANT) is essential for binding specificity. The crystal growth of HA was found to be modulated by particular peptides.

Artificial calcium phosphate crystals with controlled sizes and shapes have been widely used in biomedical and dental applications. ${ }^{6}$ Various morphologies of HA, such as fine particles, ${ }^{7}$ hexagonal rods,${ }^{8}$ and thin plates, ${ }^{9}$ were synthesized by precipitation in a mixture of solutions containing calcium and phosphate ions ${ }^{10-15}$ and transformation of various solid precursor crystals. ${ }^{16-18}$ The next great challenge is the control of the orientation of HA nanocrystals mimicking the enamel structures. In the present work, we fabricated highly oriented columnar structures of HA similar to dental enamel through a controlled crystal growth method in a supersaturated solution. Various approaches have been reported for the preparation of oriented architectures mimicking natural bones. ${ }^{19-21}$ Mesoscopically-ordered bone-mimetic nanocomposites were fabricated through mineralization of polymerized liquid crystals. ${ }^{21}$ An organized structure of a fluorapatite (FA)-gelatin system was shown to resemble the biosystem in both bone and dentine. ${ }^{22} \mathrm{~A}$ direct growth method to produce enamellike prism structures of FA on metal plates was demonstrated using a hydrothermal technique. ${ }^{23}$ The enamel-like HA bundle structures were obtained with monolayers of surfactants at the air-water interface. ${ }^{24}$ Spatial organization of HA nanorods on a functionalized substrate was achieved via crystal growth with gelatin as a structure-directing agent. ${ }^{25}$ Despite these efforts, the oriented structure of HA bundles has not been sufficiently controlled in artificial systems. Therefore, the production of enamel-like columnar structures toward 
biomedical and dental applications remains challenging in the field of materials chemistry.

Sheet-like HA crystals are commonly prepared in a simulated body fluid (SBF) containing inorganic ions nearly equal to those of human blood plasma., ${ }^{9,26}$ Nanometric lowdimensional forms, such as sheets and needles elongated in the $c$ axis, were produced with phosphate-surplus or calciumdeficient HA in an SBF-based solution at human body temperature. ${ }^{27}$ The enamel-like columnar structures were fabricated on a crystalline substrate in the SBF-based system. ${ }^{19}$ Epitaxial growth on the $c$-face HA substrates was successfully controlled by changing the conditions. However, highly controlled growth techniques are required to promote the formation of oriented HA nanocrystals at a specific site without the crystalline substrate.

In the current research, enamel-mimetic apatite films consisting of $c$-axis-oriented nanorods were fabricated by a two-step crystal growth method in an aqueous solution system that was based on an SBF. The nucleation of apatite crystals was initiated with the monolayer of a specific artificial peptide binding to the $c$ face of HA. The formation of $c$-axisoriented films with apatite microrods was promoted through geometric selection in the presence of fluoride ions. The subsequent growth with $\mathrm{D}$-aspartic acid produced the enamel-like structure consisting of oriented nanorods on the basal microrods. The stepwise crystal growth controlled by the specific artificial peptide, fluoride ion, and aspartic acid could be utilized for fabrication of well-organized biomaterials that consist of oriented nanoscale HA nanocrystals.

\section{Experimental}

Formation of HA films on the peptide monolayer

An artificial linear peptide (NPPTRQTKPKRVANTN, Scheme 1) that binds to the $c$ face of HA was used to promote the nucleation of HA. A stearoyl group was bound to the N-terminus of the peptide to form a molecular layer at the air-water interface. A Langmuir monolayer of the peptide was prepared in aqueous solution by spreading a $0.4 \mathrm{mg} \mathrm{cm}^{-3}$ solution of the peptide dissolved in a mixture of dimethyl sulfoxide and chloroform. Isotherms of the surface pressure and area of the peptide monolayer were obtained using a United System Integrators FSD-50 in pure water and in the mineralizing solution, i.e., SBF at room temperature. A common SBF is the buffered mineralization solution containing the various ions of human blood plasma. ${ }^{8}$ In the present study, we used an SBF-based solution $\left(\mathrm{s}^{\left.-\mathrm{SBF}_{1.0}\right)}\right.$ simplified by the removal of minor ions, such as $\mathrm{Mg}^{2+}, \mathrm{SO}_{4}{ }^{2-}$, and $\mathrm{HCO}_{3}{ }^{-} \cdot \mathrm{S}_{-} \mathrm{SBF}_{1.0}$ was prepared by mixing $\mathrm{HCl}$ (Junsei Chemical), $\mathrm{CaCl}_{2} \cdot 2 \mathrm{H}_{2} \mathrm{O}$ (Junsei Chemical), $\mathrm{Na}_{2} \mathrm{HPO}_{4}$ (Junsei Chemical), and $\mathrm{NaCl}$ (Kanto Chemical) with purified water. The concentrations of $\mathrm{Ca}^{2+}, \mathrm{HPO}_{4}{ }^{2-}, \mathrm{Na}^{+}$, and $\mathrm{Cl}^{-}$were $2.5,1.0,141.0$, and 165.0 $\mathrm{mM}$, respectively. The $\mathrm{pH}$ was adjusted to a certain value between 6.4 and 7.2 by adding tris(hydroxymethyl)aminomethane (Junsei Chemical) to control the growth conditions of HA crystals. We also increased the ion

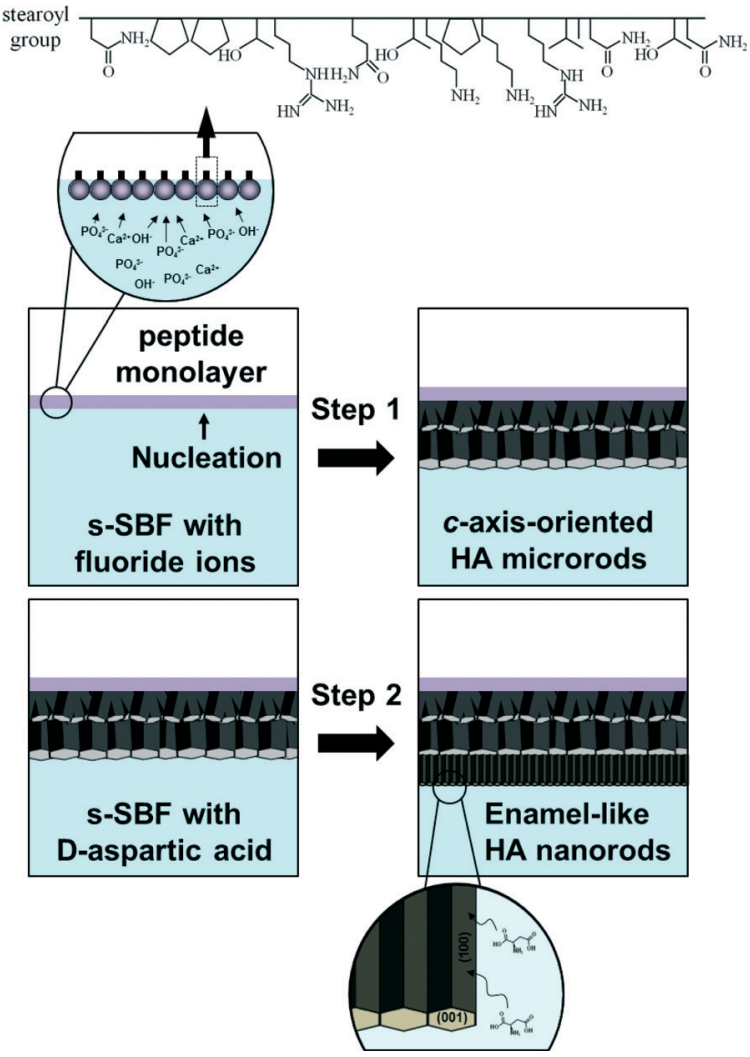

Scheme 1 Schematic representation of the $c$-face-binding peptide and the fabrication process of enamel-like apatite nanorods using the peptide monolayer in $\mathrm{s}-\mathrm{SBF}_{x}$. The $\mathrm{c}$-axis-oriented microrods are grown under the peptide monolayer with fluoride ions (Step 1). The enamellike nanorod array is formed under the microrods with $D$-aspartic acid (Step 2).

concentrations in the supersaturated solutions to regulate the growth rate $\left(\mathrm{s}^{-\mathrm{SBF}_{x}}, X=1.0-2.0\right)$. The ion concentrations in $\mathrm{s}^{-\mathrm{SBF}_{x}}$ were $X$ times higher than those in $\mathrm{s}-\mathrm{SBF}_{1.0}$. The molecular layer of the peptide was then prepared in $\mathrm{S}-\mathrm{SBF}_{x}$. As a control experiment, stearic acid was spread at the airwater interface instead of the peptide. The solution was kept at $38{ }^{\circ} \mathrm{C}$ for a certain period. The resultant products were washed with pure water and air-dried at room temperature for $24 \mathrm{~h}$.

\section{Effects of fluoride ion}

Sodium fluoride (Kanto Chemical) was added to $\mathrm{s}^{-\mathrm{SBF}_{x}}(X=$ 1.0-2.0) to study the effect of the fluoride ion on the crystal growth of HA. The concentration of the fluoride ion was set at a specific value in the range from 0.53 to $1.1 \mathrm{mM}$, and the $\mathrm{pH}$ was adjusted to 6.8. The solution was kept at $38^{\circ} \mathrm{C}$ for 24-120 h. The preparation conditions were adjusted according to a previous study. ${ }^{28}$

\section{Preparation of enamel-like oriented nanorods}

As shown in Scheme 1, we prepared enamel-like oriented HA nanorods on the basal layer consisting of $c$-axis-oriented HA microrods produced with fluoride ions. The basal layer of HA 
microrods was obtained under the peptide monolayer in s$\mathrm{SBF}_{1.2}$ containing fluoride ions at $38^{\circ} \mathrm{C}$ for $120 \mathrm{~h}$ (Step 1). Addition of D-aspartic acid (Wako Pure Chemical) to $\mathrm{s}^{-\mathrm{SBF}_{x}}$ was effective for miniaturization of HA rods grown in the solutions. Epitaxial growth was achieved on the basal layer at $38{ }^{\circ} \mathrm{C}$ in s-SBF ${ }_{1.0}(\mathrm{pH}$ 6.4) that contained $8.3 \mathrm{mM}$ D-aspartic acid (Step 2).

\section{Characterisation}

The structures of the products were characterized using a field-emission scanning electron microscope (FESEM, Hitachi S-4700) and an environmental scanning electron microscope (ESEM, FEI Inspect S50) equipped with an energy-dispersive X-ray spectrometer (EDX, Bruker Quantax). The X-ray diffraction (XRD) patterns were recorded using a Bruker D8 Discover. The products were analyzed using the $\mathrm{KBr}$ method by Fourier transform infrared adsorption (FT-IR, Jasco FT-IR 4000).

\section{Results and discussion}

\section{Formation of peptide monolayers}

Fig. 1 shows the surface pressure-area $(\pi-A)$ isotherms of the peptide having a stearoyl group in pure water and $\mathrm{s}-\mathrm{SBF}_{1.6}$. The $\pi$ value increased linearly with decreasing $A$, indicating the formation of a stable monolayer of the peptide. From the $\pi-A$ isotherms, the occupied area of the peptide molecule was estimated to be 42 and $38 \mathrm{~nm}^{2}$ in water and s-SBF ${ }_{1.6}$, respectively. The difference in the isotherms is indicative of the interactions of the peptide monolayers with various ions.

\section{Formation of self-standing HA films under the peptide monolayer}

According to the $\pi-A$ isotherms, we obtained peptide monolayers in s-SBF by adjusting the molecular concentration at the air-water interface. As shown in Fig. 2, white products were observed with the peptide monolayer at the air-water interface in $\mathrm{s}^{-\mathrm{SBF}_{1.0}}$ at $\mathrm{pH} 7.2, \mathrm{~s}-\mathrm{SBF}_{1.6}$ at $\mathrm{pH}$ 6.8-7.2, and s$\mathrm{SBF}_{2.0}$ at $\mathrm{pH} 6.0-7.2$ for $24 \mathrm{~h}$. In the absence of the peptide monolayer or the presence of a monolayer of stearic acid, no products were observed in the system. On the other hand, a

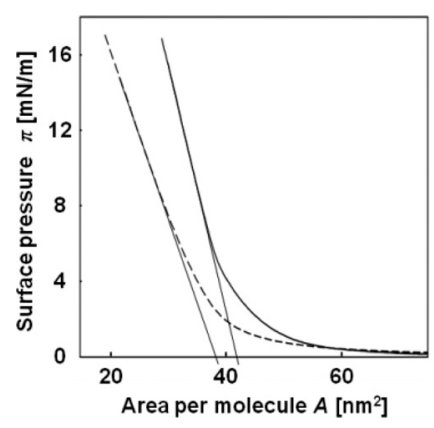

Fig. 1 Surface pressure and area $(\pi-A)$ isotherms of the peptide in pure water (solid line) and s-SBF 1.6 at pH 6.8 (broken line).
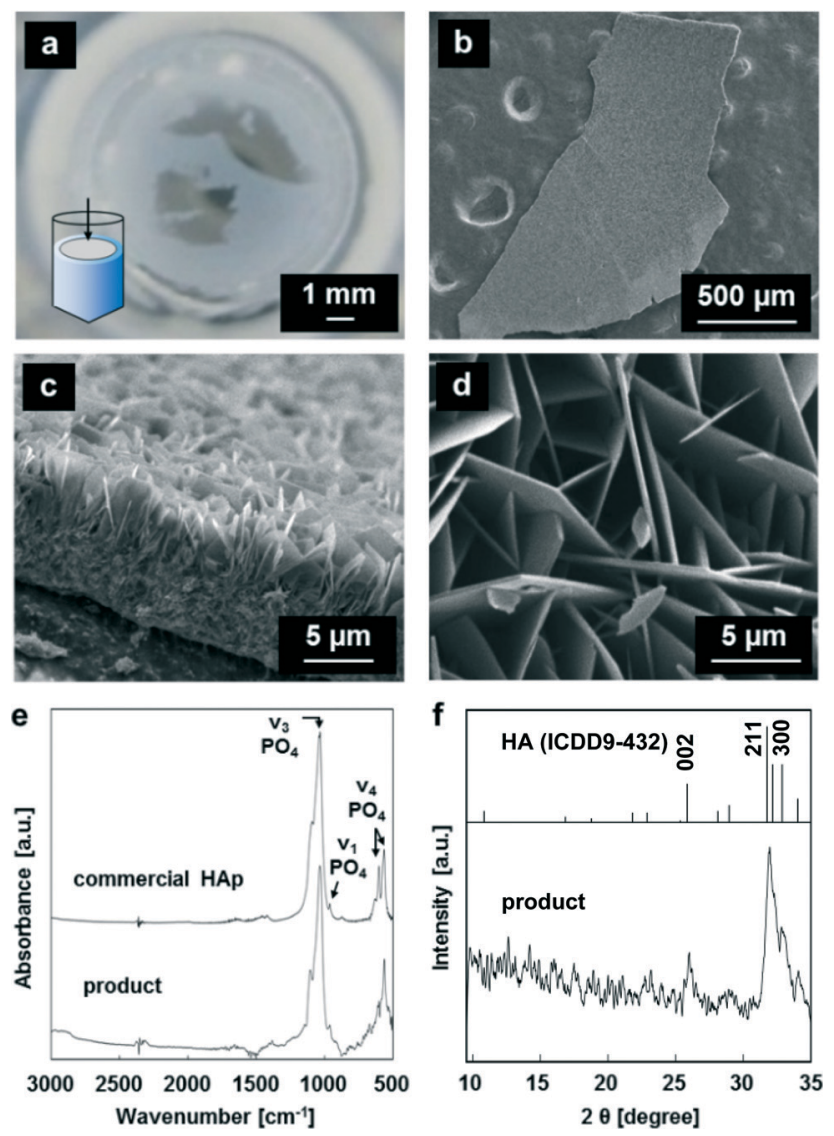

Fig. 2 Typical photograph (a) and SEM images (b, c) of the products under the peptide monolayer at the air-water interface of $\mathrm{s}-\mathrm{SBF}_{2.0}$ at $\mathrm{pH}$ 7.2. Typical SEM image (d), FT-IR (e), and XRD pattern (f) of the products under the peptide monolayer at the air-water interface of $\mathrm{s}$ $\mathrm{SBF}_{1.6}$ at $\mathrm{pH} 6.8$.

self-standing white film was formed with the peptide monolayer (Fig. 2a). The self-standing films $c a .20 \mu \mathrm{m}$ in thickness were composed of nanoplates $100-500 \mathrm{~nm}$ thick that were grown from the monolayer (Fig. 2d). According to the specific diffraction signals in the XRD patterns and the absorption bands at 565 and 604, 962, and $1020 \mathrm{~cm}^{-1}$ assignable to $\nu_{4}$, $v_{1}$, and $v_{3}$ vibration modes of $\mathrm{PO}_{4}$, respectively, in the FT-IR spectra, the products were identified as HA (Fig. 2e and f). These results indicate that the peptide monolayer induced the formation of HA through heterogeneous nucleation in the supersaturated solution. However, the specific crystallographic orientation was not observed for the produced films consisting of HA plates.

\section{Formation of $c$-axis-oriented films with fluoride ions}

When $0.53 \mathrm{mM}$ fluoride ions was added to $\mathrm{s}-\mathrm{SBF}_{1.6}$, a selfstanding film consisting of nanorods $c a .250 \mathrm{~nm}$ in diameter was produced at the interface (Fig. $3 \mathrm{a}$ and $\mathrm{b}$ ). The thickness of the film was found to be $\sim 15 \mu \mathrm{m}$ after the oriented growth under the peptide monolayer for $24 \mathrm{~h}$. The intense 002 diffraction peak was clearly observed in the XRD pattern of the film (Fig. 3f). Because the 002 signal was greater than the 300 

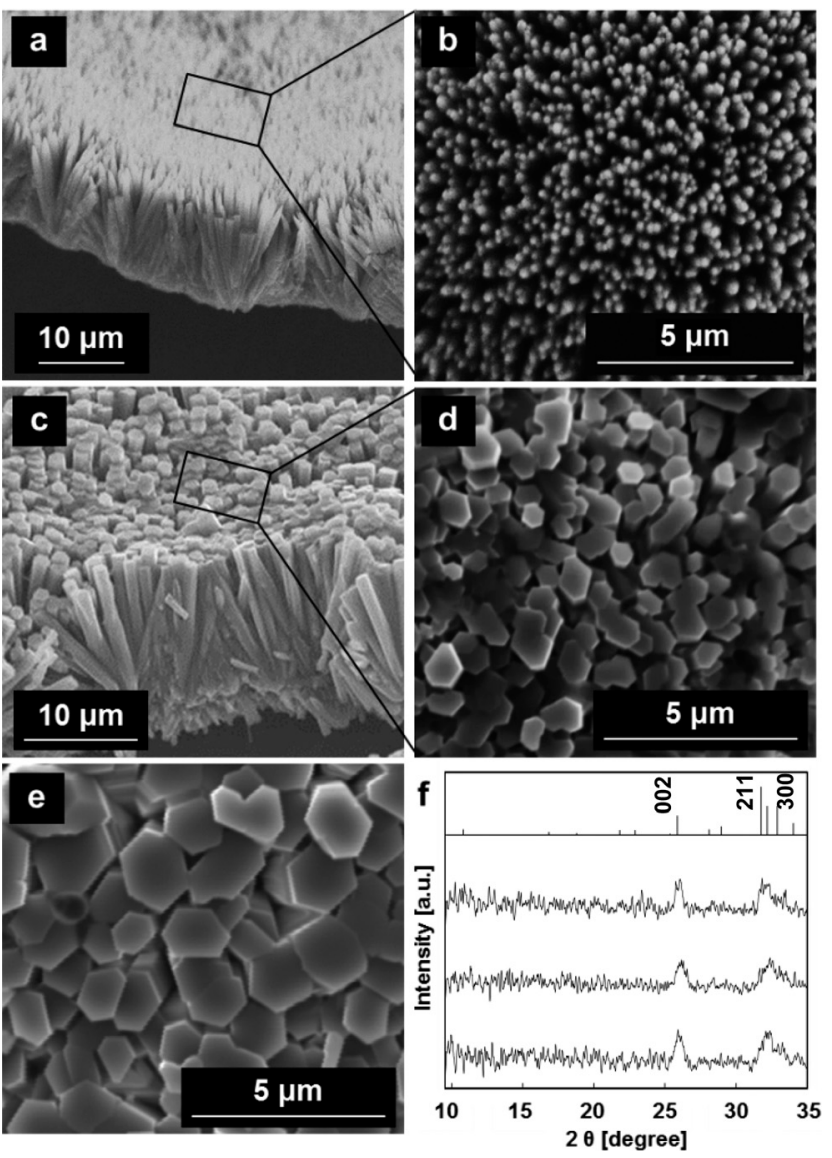

Fig. 3 SEM images (a-e) and XRD patterns (f) of the films grown in $s-\mathrm{SBF}_{1.6}$ with fluoride ions at $\mathrm{pH}$ 6.8. The products were grown in $\mathrm{s}-\mathrm{SBF}_{1.6}$ with $\left[\mathrm{F}^{-}\right]=0.53 \mathrm{mM}(\mathrm{a}, \mathrm{b}, \mathrm{i})$, with $\left[\mathrm{F}^{-}\right]=1.1 \mathrm{mM}(\mathrm{c}, \mathrm{d}$, ii), and in $\mathrm{s}-\mathrm{SBF}_{1.2}$ with $\left[\mathrm{F}^{-}\right]=1.1 \mathrm{mM}$ (e, iii).

reflection, the nanorods in the films were preferentially oriented with their $c$-axes perpendicular to the substrate. The radial growth of the nanorods from a nucleation point was observed in the cross-sectional image. Thus, the oriented growth of the nanorods was achieved through geometric selection. Because we confirmed the presence of fluoride ions in the film by EDX, we can infer that the hexagonal rods were produced through substitution of hydroxy groups with fluoride ions. Consequently, we obtained the FA or fluorinedoped HA film consisting of $c$-axis-oriented nanorods that were preferentially aligned on the surface.

The rod diameter increased to $\sim 1 \mu \mathrm{m}$ with the formation of hexagonal facets by increasing the fluoride concentration up to $1.1 \mathrm{mM}$ (Fig. 3c and d). According to the enhanced 002 signal, the degree of the $c$-axis orientation was improved by increasing the fluoride ion concentration. Furthermore, the width of the hexagonal rods gradually increased to $\sim 2 \mu \mathrm{m}$ for $120 \mathrm{~h}$ (Fig. 3e). These oriented architectures are similar to the rod array of the enamel layer. However, the films were relatively porous with a low concentration of fluoride ions (Fig. 3b), and the rods were very thick with a high concentration of fluoride ions (Fig. 3d) as compared with the biogenic enamel structure.
Formation of enamel-like architectures through the subsequent growth with D-aspartic acid

As shown in Scheme 1, we fabricated enamel-like architectures consisting of $c$-axis-oriented HA nanorods by subsequent growth on the basal microrods prepared with fluoride ions with the peptide monolayer (Fig. 4a and c). The array composed of hexagonal rods $1-2 \mu \mathrm{m}$ in diameter was used as the basal layer (Step 1) (Fig. 3e). In a previous study, we reported that the selective attachment of DL-aspartic acid to $\mathrm{Ca}^{2+}$ on the $a$ face decreases the diameter of the HA rods. ${ }^{19}$ We confirmed that D-aspartic acid has the same effect as DL-aspartic acid. Thus, nanorod arrays would be produced in the presence of $\mathrm{D}$-aspartic acid. In the progressive stage (Step 2), the nanorods $c a .100 \mathrm{~nm}$ in diameter were formed through epitaxial growth on the basal layer (Fig. 4b). The XRD profiles after the subsequent growth were not changed from the basal layer. Because D-aspartic acid was identified by characteristic absorption bands around $1200-1700 \mathrm{~cm}^{-1}$ in FT-IR spectra (Fig. 4d), the specific adsorption of D-aspartic acid on the $a$ faces decreased the size of the nanorods. In consequence, the enamel-like oriented HA architectures were obtained under the peptide monolayer by a two-step controlled crystal growth method. When aspartic acid was added to the first step, the $c$-axis-oriented HA architectures were not produced at the interface due to the strong interaction of the organic molecule to the nucleation site. Thus, the subsequent growth on the basal layer prepared with fluoride ions is valid for the synthesis of nanometric-oriented architectures.

\section{Conclusions}

A two-step controlled crystal growth technique was developed to produce enamel-like oriented nanorods using a specific
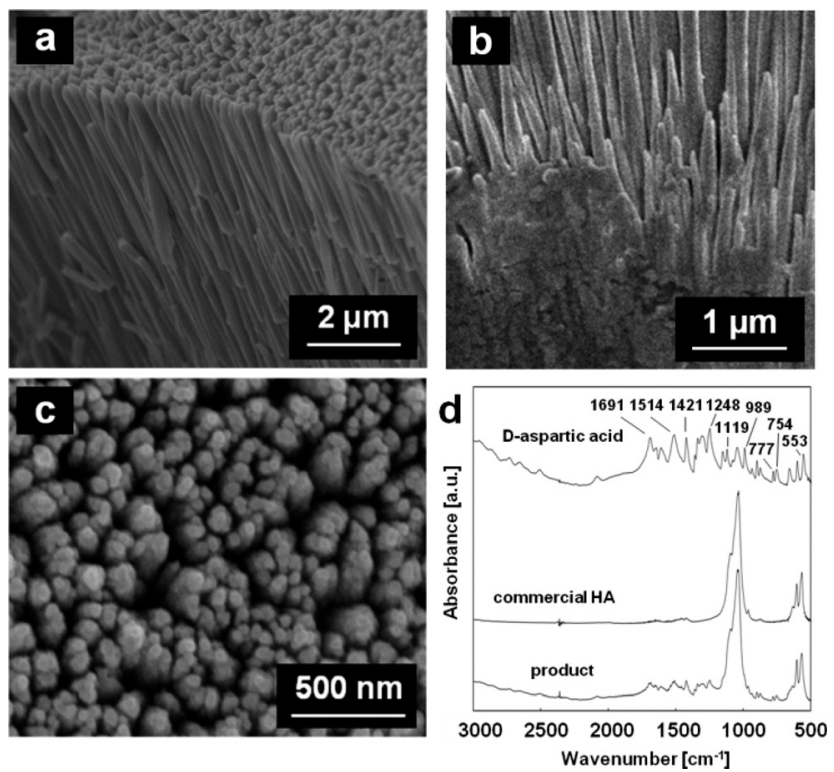

Fig. 4 SEM images: cross-sectional views (a, b), plane view (c) and FTIR spectra (d) of the products on the basal layer of the oriented microrods grown in S-SBF 1.0 with D-aspartic acid for $120 \mathrm{~h}$. 
artificial peptide, fluoride ions, and D-aspartic acid. The monolayer of the peptide binding to the $c$ face of HA was used as the nucleation site at the air-water interface. Selfstanding films with $c$-axis-oriented microrods were formed through geometric selection under the monolayer in an aqueous solution system that was based on a simulated body fluid containing fluoride ions. The subsequent growth with aspartic acid produced the enamel-like structure consisting of oriented nanorods on the basal microrods. The controlled growth with the specific artificial peptide is applicable for fabricating well-organized biomaterials that consist of oriented nanoscale HA crystals.

\section{Acknowledgements}

This work was partially supported by a Grant-in-Aid for Scientific Research (no. 22107010 and 22107007) on Innovative Areas of "Fusion Materials: Creative Development of Materials and Exploration of Their Function through Molecular Control" (area no. 2206) from the Ministry of Education, Culture, Sports, Science and Technology from Japan Society of the Promotion of Science. We thank Profs. Y. Einaga and T. Yamamoto for their experimental assistance in measurements of the surface pressure and area isotherms of the peptide.

\section{Notes and references}

1 L. Li, C. Mao, J. Wang, X. Xu, H. Pan, Y. Deng, X. Gu and R. Tang, Adv. Mater., 2011, 23, 4695.

2 T. Nakano, K. Kaibara, T. Ishimoto, Y. Tabata and Y. Umakoshi, Bone, 2012, 51, 741.

3 Y. J. Lee, H. Yi, W. J. Kim, K. Kang, D. S. Yun, M. S. Strano, G. Ceder and A. M. Belcher, Science, 2009, 324, 1051.

4 M. Gungormus, H. Fong, I. W. Kim, J. S. Evans, C. Tamerler and M. Sarikaya, Biomacromolecules, 2008, 9, 966.

5 S. Ono, T. Tsuji, Y. Oaki and H. Imai, RSC Adv., 2013, 3, 1885.

6 K. Lin, C. Wu and J. Chang, Acta Biomater., 2014, 10, 4071.

7 D. Wang and F. Caruso, Adv. Mater., 2001, 13, 350.

8 H. Ito, Y. Oaki and H. Imai, Cryst. Growth Des., 2003, 8, 1055.
9 T. Kokubo and H. Takadama, Biomaterials, 2006, 27, 2907.

10 I. S. Neira, F. Guitian, T. Taniguchi, T. Watanabe and M. Yoshimura, J. Mater. Sci., 2008, 43, 2171.

11 I. S. Neira, Y. V. Kolen'ko, O. I. Lebedev, G. V. Tendeloo, H. S. Gupta, F. Guitian and M. Yoshimura, Cryst. Growth Des., 2009, 9, 466.

12 K. Ioku, S. Yamauchi, H. Fujimori, S. Goto and M. Yoshimura, Solid State Ionics, 2002, 151, 147.

13 M. J. Olszta, X. Cheng, S. S. Jee, R. Kumar, Y. Y. Kim, M. J. Kaufman, E. P. Douglas and L. B. Gower, Mater. Sci. Eng., R, 2007, 58, 77.

14 S. Suzuki, M. Ohgaki, M. Ichiyanagi and M. Ozawa, J. Mater. Sci. Lett., 1998, 17, 381.

15 B. Viswanath and N. Ravishankar, Biomaterials, 2008, 29, 4855.

16 W. E. Brown, Nature, 1962, 196, 1048.

17 W. E. Brown, Clin. Orthop. Relat. Res., 1966, 44, 205.

18 M. D. Francis and N. C. Webb, Calcif. Tissue Res., 1971, 6, 335.

19 W. Wang, Y. Oaki, C. Ohtsuki, T. Nakano and H. Imai, J. Asian Ceram. Soc., 2013, 1, 143.

20 S. Hayakawa, Y. Li, K. Tsuru, A. Osaka, E. Fujii and K. Kawabata, Acta Biomater., 2009, 5, 2152.

21 W. He, A. K. Rajasekharan, A. R. Tehrani-Bagha and M. Andersson, Adv. Mater., 2015, 27, 2260.

22 P. Simon, D. Zahn, H. Litchte and R. Kniep, Angew. Chem., Int. Ed., 2006, 45, 1911.

23 H. Chen, Z. Tang, J. Liu, K. Sun, S. R. Chang, M. C. Peters, J. F. Mansfield, A. Czajka-Jakubowska and B. H. Clarkson, Adv. Mater., 2006, 18, 1846.

24 Y. Xu, G. Ma, X. Wang and M. Wang, Cryst. Growth Des., 2012, 12, 3362.

25 Y. Tseng, M. E. Birkbak and H. Birkedal, Cryst. Growth Des., 2013, 13, 4213.

26 T. Kokubo, S. Ito, T. Huang, T. Hayashi, S. Sakka, T. Kitsugi and T. Yamamuro, J. Biomed. Mater. Res., 1990, 24, 331.

27 T. Kobayashi, S. Ono, S. Hirakura, Y. Oaki and H. Imai, CrystEngComm, 2012, 14, 1143.

28 Y. Fan, J. R. Nelson, J. R. Alvarez, J. Hagan, A. Berrier and X. Xu, Acta Biomater., 2011, 7, 2293. 